\title{
The Efficacy of Nature-Friendly Chemicals Eugenol and Sodium Bicarbonate against Post-Harvest Botrytis cinerea in Two Pepper Cultivars
}

\author{
Ismet Yildirim ${ }^{1}$ and Mustafa Sakaldas ${ }^{2 *}$ \\ ${ }^{1}$ Plant Protection Department, Faculty of Agriculture, Düzce University, Düzce, Türkiye \\ ${ }^{2}$ Food Processing Department, Lapseki Vocational School, Çanakkale Onsekiz Mart University, Çanakkale, Türkiye \\ *For correspondence: msakaldas@yahoo.com \\ Received 14 December 2020; Accepted 15 February 2021; Published 16 April 2021
}

\begin{abstract}
Grey mold, caused by Botrytis cinerea, is the most important pre-harvest and post-harvest disease of pepper. The disease leads to huge losses in quality and yield of pepper. Synthetic fungicides should not be used because of their harmful residues in the fruits postharvest. Hence, alternative chemicals have gained more importance for human health now-a-days. In this study, the postharvest effectiveness of eugenol and sodium bicarbonate $\left(\mathrm{NaHCO}_{3}\right)$ to B. cinerea was determined on two pepper varieties, 'Demre' and 'Charleston' obtained from pepper fields in Çanakkale. In essay the Eugenol was used at dosages of 0.75 and $1.5 \%$, while sodium bicarbonate was used at dosages of 0.5 and $1.0 \%$. Pepper varieties 'Demre' and 'Charleston' showed significantly different sensitivities against grey mold disease $(P<0.01)$, and this case reflected also to the efficacies of alternative chemicals. During eight days of storage, Charleston was more sensitive to B. cinerea than 'Demre' peppers. $\mathrm{NaHCO}_{3}$ at high dosage (1.0\%) completely inhibited the disease on 'Charleston' and 'Demre' peppers. The lower dose of $\mathrm{NaHCO}_{3}$ (i.e., $0.5 \%$ ) was also highly effective in 'Demre' (providing 95\% reduction in the disease) but its efficacy was a little lower for 'Charleston' variety (84\%). Efficacy (83.7\%) of eugenol at dosage of $1.5 \%$ to B. cinerea on 'Demre' was found to be like $\mathrm{NaHCO}_{3}$ at dosage $0.5 \%$ on 'Charleston' peppers. Alternative chemicals had no adverse effects on pepper varieties. It is concluded that both tested nature-friendly chemicals (Eugenol and sodium bicarbonate) could be used (postharvest) against to B. cinerea on peppers. (C) 2021 Friends Science Publishers
\end{abstract}

Keywords: Grey mold; Alternative control; Postharvest; Pepper; Chemicals

\section{Introduction}

Postharvest diseases are one of the most important problems of crops during storage period. If postharvest diseases are not controlled sufficiently, they may cause huge losses in the quality and yield of crops. The losses caused by postharvest diseases are estimated between 20-50\% per year (Narayanasamy 2006). B. cinerea, causing pre- and postharvest losses, is probably one of the most common and widely distributed diseases of vegetables, fruits, and even field crops throughout the world (Elad 1994).

If grey mold disease is not prevented adequately, it may cause important losses in yield and quality (ColeySmith 1980; Baraldi et al. 2002). In Turkey, grey mold and black rot (Alternaria alternata) are the most economically important postharvest diseases of pepper. Grey mold and other postharvest diseases may be controlled by classical fungicides; however, most of the traditional fungicides embody the risk of leaving remnants on products and have negative effects on humans, animals and environment
(Agrios 2005; Wightwick and Allinson 2007). Furthermore, $B$. cinerea may easily develop races with high resistance against many synthetic fungicides (Abou-Jawdah and Itani 1995; Archbold et al. 1997).

In this context, recent studies have focused on alternative chemicals, biological agents and plant extracts for controlling the pathogens (Skirdal and Eklund 1993; Farooq et al. 2011). Plant extracts, sodium and potassium salts and some antimicrobial food additives have gained importance in the control of pathogens. Nowadays, especially, salts, like sodium and potassium, and antimicrobial food additives have attracted attention in the control of pathogens. In the recent studies against postharvest diseases with alternative substances, sodium bicarbonate and eugenol are remarkable. In these studies, both alternative chemicals have been found effective against various phytopathogens (Yildirim and Yapici 2007; Wang et al. 2010; Romanazzi et al. 2012). The objective of the present work was to determine the effectiveness of sodium bicarbonate and eugenol against grey mold disease on peppers after harvest.

To cite this paper: Yildirim I, M Sakaldas (2021). The efficacy of nature-friendly chemicals eugenol and sodium bicarbonate against post-harvest Botrytis Cinerea in two pepper cultivars. Intl J Agric Biol 25:1126-1130 


\section{Materials and Methods}

\section{Plant material}

Peppers (Capsicum annuum L.) cvs. Charleston F1 and Demre F1 were selected manually from commercial orchards in Çanakkale (Turkey) after harvest and used as plant material. The study was carried out between May-July 2014 in Çanakkale Onsekiz Mart University Agriculture Faculty Plant Protection Department Laboratory and Cold Storage Facilities.

\section{Origin of Botrytis cinerea isolate and inoculum}

B. cinerea isolate was obtained from diseased pepper plant in Çanakkale-Turkey. Isolate which was on Potato Dextrose Agar (PDA), were developed at $21^{\circ} \mathrm{C}$ in the incubator and to get the stock cultures, it was transferred to tubes which included PDA. Conidia were harvested two-weeks-old cultures that were growing on PDA at $21^{\circ} \mathrm{C}$ under $12 \mathrm{~h}$ light/dark periods. Conidia dislodged by rubbing the surface area with glass rod. Fungal suspension was filtered through two layers of fine sterile muslin to remove the mycelium and other fragments. Spore suspension was then counted with a haemocytometer and adjusted to $10^{6}$ spores $\mathrm{mL}^{-1}$. For inoculation, the pepper fruits were wounded in the stem and end region by means of a sterile pipette tip. They were inoculated with $60 \mu \mathrm{L}$ spore suspension from both the wounded sides and incubated in dark storage at $20-22^{\circ} \mathrm{C}$ for $12 \mathrm{~h}$.

\section{Treatments and storage conditions}

Eugenol and sodium bicarbonate $\left(\mathrm{NaHCO}_{3}\right)$ were used as nature-friendly alternative chemicals to the use of fungicides for controlling postharvest disease $B$. cinerea in peppers. Some properties of both chemicals are given in Table 1. After incubation, peppers were treated with different doses of eugenol and sodium bicarbonate. Eugenol was applied in warm water at $47 \pm 1^{\circ} \mathrm{C}$. The treatment doses are given in Table 1 . Besides, control fruits were only treated with warm water. Then all the fruits were kept on air dry at naturally room temperature for 1 hour. Peppers were stored at $9-10^{\circ} \mathrm{C}$ and $85-90 \%$ relative humidity conditions after inoculations for 8 days, and the daily improvement of grey mold was measured both sides of the peppers with digital calipers.

\section{Experiment design and statistical analysis}

The experiment was arranged in completely randomized design with three replications. Ten pepper fruits were assessed for each replication. Analysis of variance was conducted on the efficacy of the test chemicals by using 'Minitab 16 Software' and means were compared by using 'Tukey's method.

\section{Results}

According to results, lesion diameter showed an increase especially on untreated pepper fruits during the storage duration. Infected area developed significantly after five days after inoculation. Susceptibilities of artificially inoculated places (tip and middle) of fruits against $B$. cinerea were not different, but both pepper varieties showed different response against pathogen. 'Charliston' was more sensitive against fungus than 'Demre' $(P<0.01)$. Meantime, lesion development was significantly different according to varieties at $6^{\text {th }}, 7^{\text {th }}$ and $8^{\text {th }}$ days $(P<0.05$, Fig. $1)$.

According to last $3^{\text {th }}$ days measurements after inoculation, the mean of lesion diameters on 'Charleston' was found bigger than on 'Demre' (Fig. 1). Besides significant difference between the mean diameters of lesions developed on 'Demre' was not observed, whereas the lesion development on 'Charleston' continued to increase until $8^{\text {th }}$ day $(P=0.05)$.

Lesion diameter on untreated (control) and treated pepper fruits significantly showed diversity according to varieties $(P<0.01$; Fig. 2). In Fig. 3 (a, b, c), the development of $B$. cinerea lesions in untreated (Control), sodium bicarbonate and eugenol treated pepper fruits (cv. 'Demre') were fixed.

The lesion diameters of control fruits were $43.2 \mathrm{~mm}$ on 'Charleston' and $26.8 \mathrm{~mm}$ on 'Demre' peppers, and these were significantly reduced on fruits treated with test chemicals with the increasing dose levels (Fig. 2). The highest lesion development was observed on pepper varieties treated with eugenol at $0.75 \%$ dosage, $23.7 \mathrm{~mm}$ (Charliston), $12.7 \mathrm{~mm}$ (Demre), and lesion diameter of eugenol $(1.5 \%)$ treated fruits was not significantly different than that of sodium bicarbonate $(0.5 \%)$ treated ones $(P<$ $0.01)$. However, in fruits of both pepper varieties treated with $1.0 \%$ dosage of sodium bicarbonate, no lesion development was observed (Fig. 2).

Chemical applications at postharvest had high efficacy against $B$. cinerea, and effectiveness of chemical applications showed significant differences $(P<0.01)$ according to treatment dosages eight days after of inoculation (Fig. 4).

Sodium bicarbonate at $1.0 \%$ completely inhibited gray mold caused by $B$. cinerea $(100 \%)$ in both pepper cultivars and at half dosage $(0.5 \%)$ exhibited similar effect on 'Demre' (Fig. 3). Sodium bicarbonate at $0.5 \%$ on 'Charleston' and eugenol at $1.5 \%$ on 'Demre' showed effectiveness close to each other. At half dosage $(0.75 \%)$, eugenol on 'Demre' showed similar effect at dosage of $1.5 \%$ on 'Charleston'; however, it had at least efficacy with $45.6 \%$ at dosage of $0.75 \%$ on 'Charleston' (Fig. 4).

\section{Discussion}

Nowadays, the alternative control of plant diseases has 
Table 1: Some properties of the test chemicals

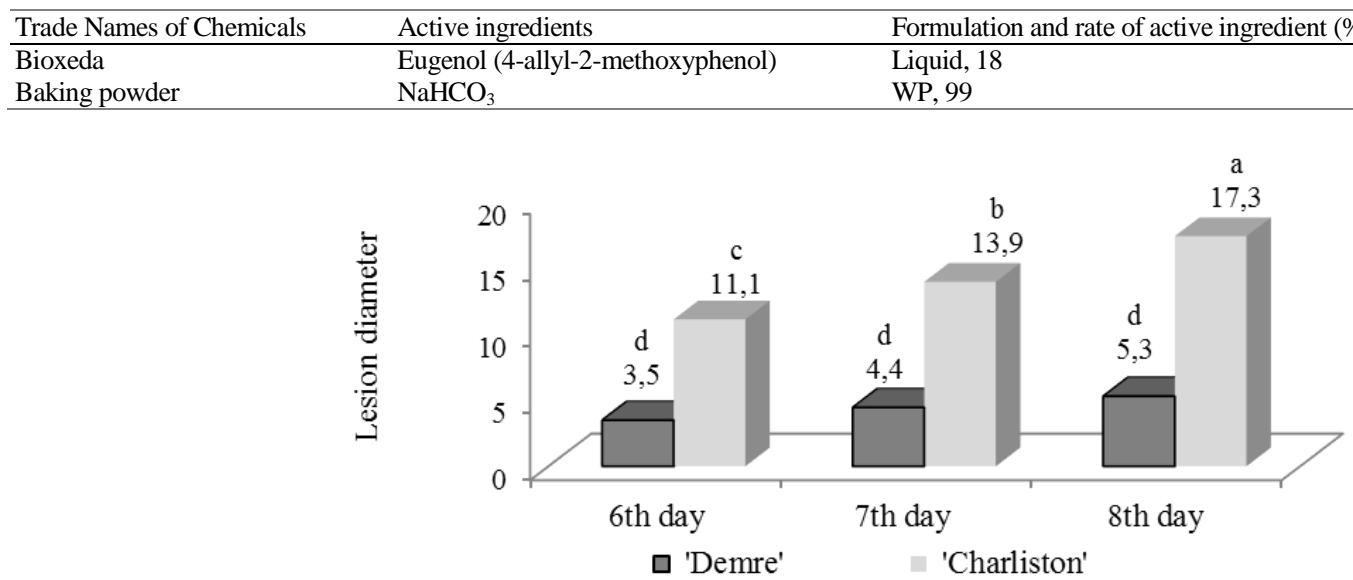

Fig. 1: Development of disease on pepper varieties

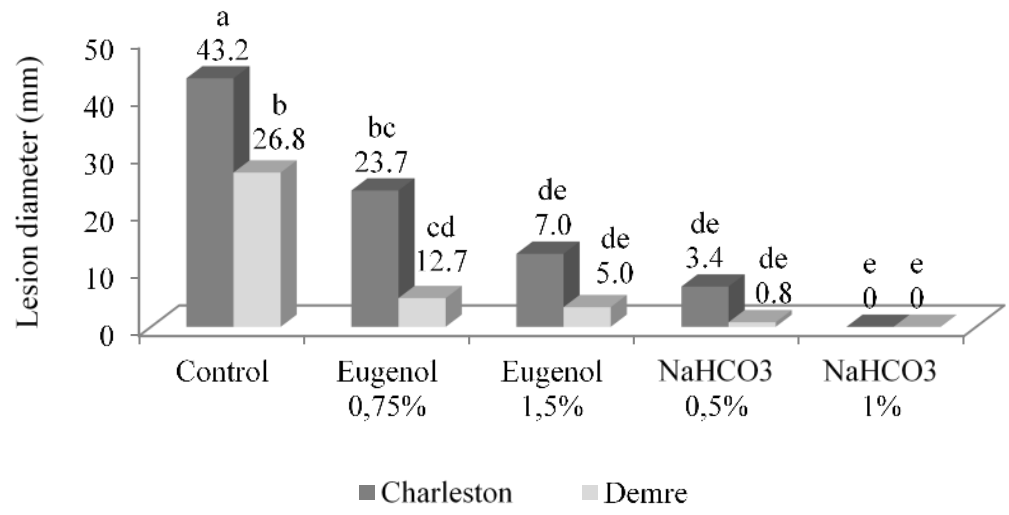

Fig. 2: Effect of chemicals on the size of lesion on pepper fruit caused by Botrytis cinerea

become more important. Especially, plant extracts, sodium and potassium salts have gained importance in the control of pathogens. In this study, the effectiveness of sodium bicarbonate and eugenol against $B$. cinerea (Grey mold disease) on two pepper varieties 'Demre' and 'Charleston' were studied during at storage conditions. 'Demre' and 'Charleston' showed different sensitivities against grey mold disease, and this case reflected also to the effectiveness of alternative chemicals. 'Charleston' was found more sensitive to $B$. cinerea during eight days of storage period than 'Demre' (Fig. 1 and Fig. 2). Difference of sensitivity of both pepper varieties to disease maybe related with ethylene production of plants in different concentration during ripening postharvest (Woltering and Doom 1988). Ethylene causes increase of the tissue sensitivity to diseases in plants, at the same time it stimulates the conidial germination and hyphal growth of $B$. cinerea (Elad 1988; Elad and Evensen 1995). In addition, pepper varieties as well as other plant varieties may have difference defense system against $B$. cinerea. Dix and Webster (1995) reported that some workers determined that the waxes extracts obtained from various plant leaves (broad bean, sugar beet, red beet, birch, lettuce, tomato, black current and chrysanthemum) had inhibitory effect on spore germination of $B$. cinerea, and this was caused by the inhibitory substances in waxes (Blakeman and Sztejnberg 1973).

Both treatment doses $(0.5$ and $1 \%)$ of sodium bicarbonate showed strong inhibition on the lesion development of $B$. cinerea in both the pepper varieties. However, its effectiveness against grey mold disease at the dosage of $0.5 \%$ on 'Charleston' was a little lower than that of on 'Demre'. Disease severity on the pepper fruits especially on 'Charleston' treated with eugenol was higher than that of sodium bicarbonate. Thus, sodium bicarbonate was more successful for the control of $B$. cinerea according to eugenol. In contrast to eugenol, sodium bicarbonate at all doses had a higher effectiveness against grey mold on both the pepper varieties. It completely inhibited the disease at $1 \%$ dose and showed similar effect at 'Demre' at $0.5 \%$ treatment dose. However, this effect was observed only at high dose (1\%) of the chemicals on 'Charleston'. That could be considered as a collective effect of the host resistance and effectiveness of the chemical. Sodium bicarbonate is one of 

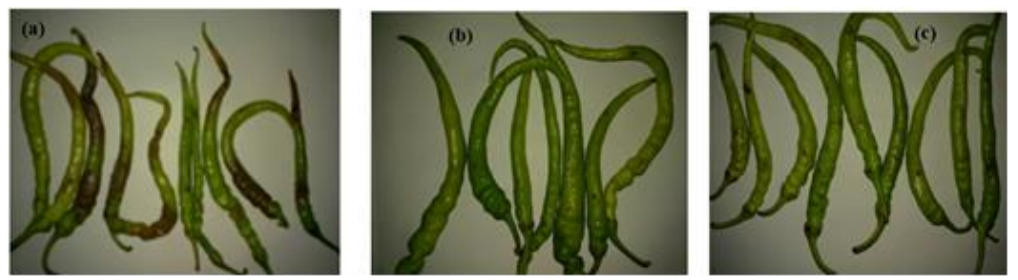

Fig. 3: In 'Demre' pepper variety, lesion development of Botrytis cinerea in untreated pepper fruits (a) and peppers treated with (b) sodium bicarbonate at $1 \%$ dosage and (c) eugenol $1.5 \%$ dosage

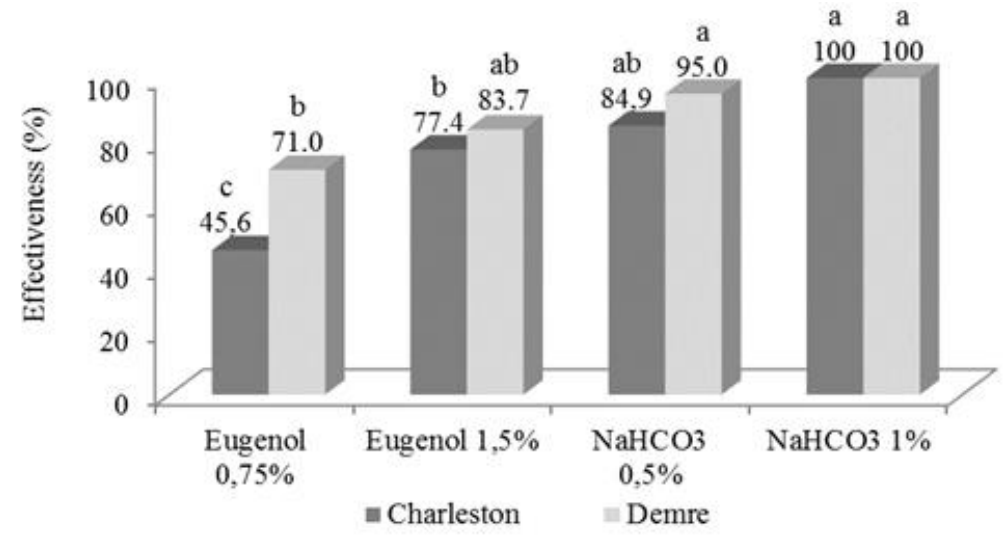

Fig. 4: Effectiveness of chemicals to grey mold caused by Botrytis cinerea on pepper fruit

the best-known alternative substances, and previously research works conducted with alternative chemicals had shown that sodium bicarbonate alone or in combination with other antifungal agents could be highly effective against numerous pre- and postharvest diseases (Palmer et al. 1997; Zaker 2014; Mlikota and Smilanick 2001).

Contrary to results of this study, it is reported that salts also including sodium bicarbonate applied to table grape after harvest did not show suppressive effect to $B$. cinerea and the preharvest-treatment on grape was more effective to mold than postharvest immersion (Youssefa and Roberto 2014). However, this study on pepper fruits artificially inoculated with $B$. cinerea after harvest demonstrated that sodium bicarbonate had strong inhibitory effect to grey mold at 0.5 and $1.0 \%$ doses on both pepper varieties 'Demre' and 'Charleston'. This difference between two studies may be due to the different sensitivities of the plants to the pathogen or due to the buffering response of $B$. cinerea to high $\mathrm{pH}$ caused by sodium bicarbonate.

Bicarbonate ion $\left(\mathrm{HCO}_{3}{ }^{-}\right)$having a buffering property in aqueous solution causes alkalinization by elevating the $\mathrm{pH}$ of environment, and this results in inhibition of the mycelial growth and conidia germination of $B$. cinerea as well as the polygalacturonase activity (Palmer et al. 1997; Fagundes et al. 2013). However, high $\mathrm{pH}$ may not be sufficient to explain the mode of action of salts in all circumstances; thus, it is reported that high $\mathrm{pH}$ of salt solution was not enough for the inhibition of $B$. cinerea on grape berries (Nigro et al. 2006). Thus, the production of extracellular enzymes (polygalacturonases, pectin methylesterases, proteases and laccases) playing important role on pathogenicity show diversity according to host and environmental factors. However, high $\mathrm{pH}$ may not be sufficient to explain the mode of action of salts in all circumstances (Wang et al. 2010; Shah et al. 2012; Fagundes et al. 2013). It is reported that the hydrogen ion concentration existing in environment controlled the ionization of salts and hence the availability of ions to the fungus, and the permeability of the plasmalemma (Dix and Webster 1995). Thus, ion uptake, enzyme activity and extracellular enzyme activity is influenced depending on $\mathrm{pH}$ values. Besides, one of the mode actions of salts is the reduction of the turgor pressures of fungal structures, and this results in the collapse and shrinkage of fungal hyphae as well (Fallik et al. 1997).

Effect of the sensitivity difference between pepper varieties was clearly observed in application of eugenol. At the low dosage $(0.75 \%)$ of eugenol, the effectiveness against the disease was found more about at $50 \%$ ratio on Demre than that of on Charleston (Fig. 2). Eugenol at high dose $(1.5 \%)$ was as effective as $\mathrm{NaHCO}_{3}$ at low dose $(0.5 \%)$. It showed high effectiveness against for eight days. It may be accepted to be successful for the control of gray mold on peppers.

Eugenol has antimicrobial activity against various fungal pathogens (Rhayour et al. 2003). In some studies, it has been observed that eugenol could inhibit hyphal growth of $B$. cinerea but had no biological activity on conidial germination. Eugenol triggers $\mathrm{H}_{2} \mathrm{O}_{2}$ production in the cytoplasm, leading to increasing free $\mathrm{Ca}^{2+}$, that lead to 
membrane binding and permeability changes and consequently destabilization and disruption of the plasma membrane (Wang et al. 2010).

As a result, it was determined that each chemical, eugenol and $\mathrm{NaHCO}_{3}$ had strong postharvest effectiveness against $B$. cinerea on peppers. In addition, the effectiveness of applied alternative chemicals was variable depending on the pepper variety of dose of the chemicals. Eugenol applied at higher dosage to $B$. cinerea on 'Demre' was found as effective as that of $\mathrm{NaHCO}_{3}$ applied at lower dosage to the pathogen on 'Charleston'. These findings mean that the resistance of plants against pathogens is an important aspect regarding the effectiveness of chemicals.

\section{Conclusion}

The eugenol and sodium bicarbonate can be used against post-harvest diseases in organic and traditional agriculture. The results of Eugenol and sodium bicarbonate against lead mold disease show difference according to sensitivities of plant varieties to pathogen. In application doses, it is necessary to pay attention to the susceptibility of plant varieties. In general, sodium bicarbonate at $0.5 \%$ dose and eugenol $1.5 \%$ can be applied by spraying at the surface of the fruit or by dipping the fruits into water containing chemical.

\section{Author Contributions}

Yildirim made the innoculum, materialized the innoculation and found literatures, Sakaldas made the measurements and assesed the statistical datas and found the plant material.

\section{Conflicts of Interes}

The authors declare that they have no conflict of interest.

\section{Data Availability}

The data will be made avaialble on acceptable requests to the corresponding author.

\section{Ethics Approval}

Not applicable.

\section{References}

Abou-Jawdah Y, H Itani (1995). Sensitivity of Botrytis cinerea isolates to fungicides used in Lebanon. In: Proceedings of $9^{\text {th }}$ Congress of the Mediterranean Phytopathology Union, Vol. 34, pp:100-108. Kuşadasi-Aydin, Türkiye

Agrios GN (2005). Plant Pathology, $5^{\text {th }}$ edn., p:952. Elsevier-Academic Press, San Diego, California, USA

Archbold DD, TR Hamiltonkemp, MM Barth, BE Langlois (1997). Identifying natural volatile compounds that control gray mold (Botrytis cinerea) during postharvest storage of strawberry, blackberry and grape. J Agric Food Chem 45:4032-4037
Baraldi E, P Bertolini, E Chierici, B Trufelli, D Luiselli (2002). Genetic diversity between Botrytis cinerea isolates from unstored and cold stored kiwi fruit. J Phytopathol 150:629-635

Blakeman JP, A Sztejnberg (1973). Effect of surface wax on inhibition of germination of Botrytis cinerea spores on beetroot leaves. Physiol Plant Pathol 3:269-278

Coley-Smith JR (1980). Sclerotia and other structures in survival. In: The Biology of Botrytis, pp:85-114. Coley-Smith JR, K Verhoeff, WR Jarvis (Eds.). Academic Press, London

Dix NJ, J Webster (1995). Fungal Ecology. Published by Chapman and Hall, London

Elad Y (1994). Biological control of grape grey mould by Trichoderma harzianum. Crop Prot 13:35-38

Elad Y (1988). Involvement of ethylene in the disease caused by Botrytis cinerea on the rose and carnation flower sand the possibility of control. Ann Appl Biol 113:589-598

Elad Y, K Evensen (1995). Physiological aspect of resistance to Botrytis cinerea. Phytopathology 85:635-643

Fagundes C, MB Pérez-Gago, AR Monteiro, L Palou (2013). Antifungal activity of food additives in vitro and as ingredients of hydroxypropyl methylcellulose-lipid edible coatings against Botrytis cinerea and Alternaria alternata on cherry tomato fruit. Intl J Food Microbiol 166:391-398

Fallik E, S Grinberg, O Ziu (1997). Potassium bicarbonate reduces postharvest decay development on bell pepper fruit. J Hortic Sci 72:35-41

Farooq M, K Jabran, ZA Cheema, A Wahid, KH Siddique (2011). The role of allelopathy in agricultural pest management. Pest Manage Sci 67:493-506

Mlikota GF, JL Smilanick (2001). Postharvest control of table grape gray mold on detached berries with carbonate and bicarbonate salts and disinfectants. Amer J Enol Viticult 52:12-20

Narayanasamy P (2006). Postharvest Pathogens and Disease Management, p:578. John Wiley and Sons, Inc., New Jersey, USA

Nigro F, L Schena, A Ligorio, I Pentimone, A Ippolito, MG Salerno (2006). Control of table grape storage rots by pre-harvest applications of salts. Postharv Biol Technol 42:142-149

Palmer CL, RK Horst, RW Langhans (1997). Use of bicarbonates to inhibit in vitro growth of Botrytis cinerea. Plant Dis 81:1432-1438

Rhayour K, T Bouchikhi, A Tantaoui-Elaraki, K Sendide, A Remmal (2003). The mechanism of bactericidal action of oregano and clove essential oils and of their phenolic major components. J Essent Oil Res 15:286-292

Romanazzi A, G Lichter, FG Mlikota, J Smilanick (2012). Recent advances on the use of natural and safe alternatives to conventional methods to control postharvest gray mold of table grapes. Postharv Biol Technol 63:141-147

Shah P, AL Powell, R Orlando, C Bergmann, G Gutiérrez-Sánchez (2012). Proteomic analysis of ripening tomato fruit infected by Botrytis cinerea. J Proteom Res 11:2178-2192

Skirdal IM, T Eklund (1993). Microculture model studies on the effect of sorbic acid on Penicillium chrysogenum, Cladosporium cladosporioides and Ulocladium atrum at different $\mathrm{pH}$ levels. J Appl Bacteriol 74:191-195

Wang C, J Zhang-Chen, HY Fan, J Shi (2010). Antifungal Activity of Eugenol against Botrytis cinerea. Trop Plant Pathol 35:137-143

Wightwick A, G Allinson (2007). Pesticide residues in victorian waterways: A review (online). Aust J Ecotoxicol 13:91-112

Woltering ED, WGV Doom (1988). Role of ethylene in senescence of petals: Morphological and taxonomical relationships. J Exp Bot 39:1605-1616

Yildirim I, BM Yapici (2007). Inhibition of conidia germination and mycelial growth of Botrytis cinerea by some alternative chemicals. Pak J Biol Sci 10:1294-1300

Youssefa K, SR Roberto (2014). Salt strategies to control Botrytis mold of 'Benitaka' table grapes and to maintain fruit quality during storage. Postharv Biol Technol 95:95-102

Zaker M (2014). Antifungal evaluation of some inorganic salts against three phytopathogenic fungi. Intl J Agric Crop Sci 7:1352-1358 